\title{
Demands, Backorders, Service Level, Lost Sales And Effective Service Level
}

Nick T. Thomopoulos, (E-mail: thomop@stuart.iit.edu), Illinois Institute of Technology

\begin{abstract}
The typical way service level is measured in industry is the demand filled over total demand. Unfilled demand becomes a backorder or lost sales. Lost sales demand is often not known or measured by the management. This paper shows how to estimate the lost sales demand and also shows how to measure an effective service level. Tables are provided for easy reference and two examples show how to apply the results of this paper to industry situations.
\end{abstract}

\section{Introduction}

One of the key measures that management uses to gauge their inventory performance is by way of the service level. A common way to measure the service level (sl) is the ratio of (demand filled) over the (recorded demand). Generally a service level of .95 or higher is demanded by the management. The reported measure of service level is often computed over all or a portion of the parts in the inventory and for a particular time period as one week, one month or one year.

A fault in the above measure of the service level is that sometimes not all of the demand on the item is known or is recorded. This happens when a customer has need for the item and the item is not available in stock. Here the demand is not satisfied and this unfilled demand becomes either a backorder or a lost sale. It is a backorder when the customer will wait for the stock to be replenished whereby the demand is subsequently filled. It is a lost sale when the customer does not wait for the stock to be replenished and drops the demand. In this latter case, the demand is mostly not recorded.

References $[1,2,3,4,5]$ show how to set the safety stock to yield a desired service level. The difficulty is that the definition on the service level is not always the same from company to company. References [2,5] give methods on how to set the safety stock when the criteria is to minimize the lost sales or the backorders.

\section{Typical data to measure the service level}

Consider the situation where the following data is available to the management and thereby is the data used to compute the service level:

$$
\begin{aligned}
& \mathrm{dr}=\text { demand recorded } \\
& \mathrm{df}=\text { demand filled from stock } \\
& \mathrm{dbo}=\mathrm{dr}-\mathrm{df}=\text { backorder demand }=\text { demand not filled till new stock arrives. }
\end{aligned}
$$

Note here that $\mathrm{dr}=(\mathrm{df}+\mathrm{dbo})$ and the backorder demand is filled as soon as new stock becomes available. With this scenario, the service level is measured as:

$$
\mathrm{sl}=\mathrm{df} / \mathrm{dr}
$$




\section{Lost sales}

When a demand occurs and the item is out of stock, often the customer will not wait for the stock to be replenished and thereby the demand is a lost sale (and not a backorder). The notation here is:

$$
\text { dls }=\text { lost sale }=\text { demand not filled }
$$

This lost sale demand is frequently not known and not recorded as demand.

\section{Effective demand and effective unfilled demand}

In essence, the demand dr listed above is not complete since it does not include the portion of demand that becomes the lost sales. For this purpose the notion of an effective demand (denoted as de) is introduced here and this is measured as follows:

$$
\mathrm{de}=\mathrm{df}+\mathrm{dbo}+\mathrm{dls} .
$$

In the same way, the unfilled demand listed earlier as dbo (backorders) is also not complete. The effective unfilled demand -- here denoted as du - becomes:

$$
\mathrm{du}=\mathrm{dbo}+\mathrm{dls}
$$

Using the above notation, note where $\mathrm{de}=\mathrm{df}+\mathrm{du}$.

\section{Effective service level}

So now the concept of an effective service level (sle) can be introduced. This is the ratio of the (demand filled) over (effective demand). Using the notation given earlier:

$$
\text { sle }=\mathrm{df} / \mathrm{de} .
$$

For most situations the effective service level cannot be measured since the effective demand de is not known.

\section{Ratio of backorders and unfilled demand} gives:

Consider another measure here denoted as $\mathrm{p}=$ (portion of unfilled demand that becomes a backorder). This

$$
\mathrm{p}=\mathrm{dbo} /(\mathrm{dbo}+\mathrm{dls})=\mathrm{dbo} / \mathrm{du}
$$

So using $\mathrm{p}$ and du (unfilled demand), the backorder and lost sales are computed as follows:

$$
\begin{aligned}
& \text { dbo }=p \times d u \\
& \text { dls }=(1-p) \times d u
\end{aligned}
$$

Consider now the data that is commonly known to the inventory management over a group of parts: $s \mathrm{l}=$ service level and $\mathrm{df}=$ filled demand. Suppose that $\mathrm{p}$ as listed above is also known or can be estimated. Then the relations below are stated and the effective demand is estimated as shown:

$$
\begin{aligned}
& \mathrm{dr}=\mathrm{df} / \mathrm{sl} \\
& \mathrm{dbo}=(1-\mathrm{sl}) \times \mathrm{dr} \\
& \mathrm{dbo}=\mathrm{p} \times \mathrm{du} \\
& \mathrm{du}=\mathrm{dbo} / \mathrm{p} \\
& \mathrm{de}=\mathrm{df}+\mathrm{du}
\end{aligned}
$$




\section{The effective service level}

Finally with de estimated, the effective service level - as listed above -- can now be measured,

sle $=\mathrm{df} / \mathrm{de}$.

Note: $\quad \mathrm{sl}=\mathrm{df} /(\mathrm{df}+\mathrm{dbo})$

sle $=\mathrm{df} /(\mathrm{df}+\mathrm{dbo}+\mathrm{dls})$

\section{Portion of backorders and portion of lost sales}

Using sle and $\mathrm{p}$, it is possible to measure the portion of demand that becomes a backorder (pbo) and the portion that becomes a lost sale (pls). These are the following:

$$
\begin{aligned}
& \text { pbo }=\mathrm{p} \times(1-\text { sle }) \\
& \text { pls }=(1-p) \times(1-\text { sle })
\end{aligned}
$$

\section{Estimating filled demand}

Sometimes it is useful to estimate the filled demand (df) when the following data are known: effective demand (de), service level (sl) and portion of unfilled demand that becomes a backorder (p). With algebraic manipulation, the estimate becomes:

$$
\mathrm{df}=(\mathrm{p} \times \mathrm{de}) /(1 / \mathrm{sl}-1+\mathrm{p})
$$

\section{Tables}

This method is used to create the entries in Tables 1, 2, 3 from values of sl (.70 to .99) and p (0.1 to 1.0). Table 1 lists the effective service level, Table 2 the associated portion of backorders and Table 3 the associated portion of lost sales.

\section{Examples}

To illustrate the results, two examples are listed below:

1. Consider a firm with annual recorded demand of $\$ 10,000,000$ and the service level is 0.95 . The backorder demand is known but not the lost sales demand. The management estimates $50 \%$ of unfilled demand become backorders $(\mathrm{p}=.5)$. In this scenario the measures are:

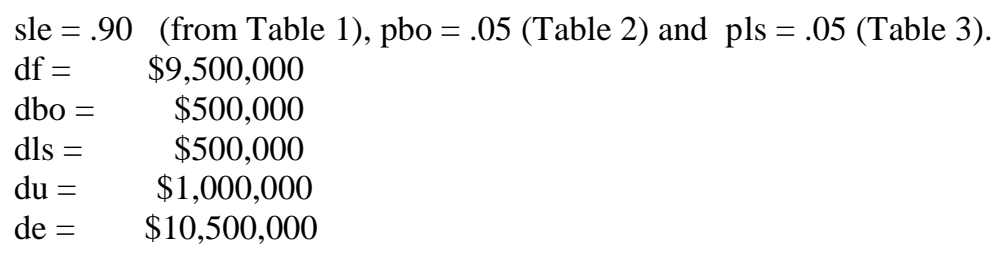

2. Suppose a situation where $\mathrm{p}=0.40$ is estimated as the portion of unfilled demand that becomes a backorder. Also, management wishes the effective service level to be sle $=0.95$. What service level should the management seek to achieve this goal. The solution is found in Table 1 that shows (when $p=0.40$ ) the service level of $\mathrm{sl}=0.98$ is needed to attain sle $=0.95$ (the effective service level). 


\section{Summary}

This paper pertains when not all demands are recorded and the service level is measured with only the recorded portion of demands. When lost sales occur, the associated demands are mostly not recorded or not known to the inventory management. This paper describes three statistics that are useful in the management control of inventory but not commonly measured. These statistics are the following : the effective service level, the portion of demand that become backorders and the portion of demand that become lost sales. The paper shows how these statistics can be measured from data typically known or estimated in the inventory operation. Three related tables are presented.

Table 1 The effective service level (sle) for selective values of sl and $p$

\begin{tabular}{|c|c|c|c|c|c|c|c|c|c|c|}
\hline sl & 0.10 & 0.20 & 0.30 & 0.40 & 0.50 & 0.60 & 0.70 & 0.80 & 0.90 & 1.00 \\
\hline---- & ---- & ----- & ---- & --1 & -sle- & ----- & ----- & ----- & ----- & \\
\hline 0.99 & 0.91 & 0.95 & 0.97 & 0.98 & 0.98 & 0.98 & 0.99 & 0.99 & 0.99 & \\
\hline 0.98 & 0.83 & 0.91 & 0.94 & 0.95 & 0.96 & 0.97 & 0.97 & 0.98 & 0.98 & 0. \\
\hline 0.97 & 0.76 & 0.87 & 0.91 & 0.93 & 0.94 & 0.95 & 0.96 & 0.96 & 0.97 & \\
\hline 0.96 & 0.71 & 0.83 & 0.88 & 0.91 & 0.92 & 0.94 & 0.94 & 0.95 & 0.96 & 0.9 \\
\hline 0.95 & 0.66 & 0.79 & 0.85 & 0.88 & 0.90 & 0.92 & 0.93 & 0.94 & 0.94 & \\
\hline 0.94 & 0.61 & 0.76 & 0.82 & 0.86 & 0.89 & 0.90 & 0.92 & 0.93 & 0.93 & 0. \\
\hline 0.93 & 0.57 & 0.73 & 0.80 & 0.84 & 0.87 & 0.89 & 0.90 & 0.91 & 0.92 & \\
\hline 0.92 & 0.53 & 0.70 & 0.78 & 0.82 & 0.85 & 0.87 & 0.89 & 0.90 & 0.91 & 0 . \\
\hline 0.91 & 0.50 & 0.67 & 0.75 & 0.80 & 0.83 & 0.86 & 0.88 & 0.89 & 0.90 & 0.91 \\
\hline 0.90 & 0.47 & 0.64 & 0.73 & 0.78 & 0.82 & 0.84 & 0.86 & 0.88 & 0.89 & \\
\hline 0.85 & 0.36 & 0.53 & 0.63 & 0.69 & 0.74 & 0.77 & 0.80 & 0.82 & 0.84 & 0.8 \\
\hline 0.80 & 0.29 & 0.44 & 0.55 & 0.62 & 0.67 & 0.71 & 0.74 & 0.76 & 0.78 & \\
\hline 0.75 & 0.23 & 0.38 & 0.47 & 0.55 & 0.60 & 0.64 & 0.68 & 0.71 & 0.73 & 0.7 \\
\hline 0.70 & 0.19 & 0.32 & 0.41 & 0.48 & 0.54 & 0.58 & 0.62 & 0.65 & 0.68 & \\
\hline
\end{tabular}

Table 2 The portion of backorders (pbo) for selective values of sl and $p$

\begin{tabular}{|c|c|c|c|c|c|c|c|c|c|c|}
\hline sl & 0.10 & 0.20 & 0.30 & 0.40 & 0.50 & 0.60 & 0.70 & 0.80 & 0.90 & 1.00 \\
\hline---- & & & & & & & & & & \\
\hline 0.99 & 0.01 & 0.01 & 0.01 & 0.01 & 0.01 & 0.01 & 0.01 & 0.01 & 0.01 & 0.01 \\
\hline 0.98 & 0.02 & 0.02 & 0.02 & 0.02 & 0.02 & 0.02 & 0.02 & 0.02 & 0.02 & 0.02 \\
\hline 0.97 & 0.02 & 0.03 & 0.03 & 0.03 & 0.03 & 0.03 & 0.03 & 0.03 & 0.03 & 0.03 \\
\hline 0.96 & 0.03 & 0.03 & 0.04 & 0.04 & 0. & 0.04 & 0.04 & 0.04 & 0.04 & \\
\hline 0.95 & 0.03 & 0.04 & 0.04 & 0.05 & 0.05 & 0.05 & 0.05 & 0.05 & 0.05 & 0.05 \\
\hline 0.94 & 0.04 & 0.05 & 0.05 & 0.06 & 0.06 & 0.06 & 0.06 & 0.06 & 0.06 & 06 \\
\hline 0.93 & 0.04 & 0.05 & 0.06 & 0.06 & 0.07 & 0.07 & 0.07 & 0.07 & 0.07 & 0.07 \\
\hline 0.92 & 0.05 & 0.06 & 0.07 & 0.07 & 0.07 & 0.08 & 0.08 & 0.08 & 0.08 & 0.08 \\
\hline 0.91 & 0.05 & 0.07 & 0.07 & 0.08 & 0.08 & 0.08 & 0.09 & 0.09 & 0.09 & 0.09 \\
\hline 0.90 & 0.05 & 0.07 & 0.08 & 0.09 & 0.09 & 0.09 & 0.10 & 0.10 & 0.10 & 0.10 \\
\hline 0.85 & 0.06 & 0.09 & 0.11 & 0.12 & 0.13 & 0.14 & 0.14 & 0.14 & 0.15 & 0.15 \\
\hline 0.80 & 0.07 & 0.11 & 0.14 & 0.15 & 0.17 & 0.18 & 0.18 & 0.19 & 0.20 & 0.20 \\
\hline 0.75 & 0.08 & 0.13 & 0.16 & 0.18 & 0.20 & 0.21 & 0.23 & 0.24 & 0.24 & 0.25 \\
\hline 0.70 & 0.08 & 0.14 & 0.18 & 0.21 & 0.23 & 0.25 & 0.27 & 0.28 & 0.29 & 0.30 \\
\hline
\end{tabular}


Table 3 The portion of lost sales (pls) for selective values of sl and $p$

\begin{tabular}{|c|c|c|c|c|c|c|c|c|c|c|}
\hline sl & 0.10 & 0.20 & 0.30 & 0.40 & 0.50 & 0.60 & 0.70 & 0.80 & 0.90 & 1.00 \\
\hline---- & & & & & $\mathrm{p} \perp \mathrm{s}-$ & & & & & \\
\hline 0.99 & 0.08 & 0.04 & 0.02 & 0.01 & 0.01 & 0.01 & 0.00 & 0.00 & 0.00 & 0.00 \\
\hline 0.98 & 0.15 & 0.07 & 0.04 & 0.03 & 0.02 & 0.01 & 0.01 & 0.00 & 0.00 & 0.00 \\
\hline 0.97 & 0.21 & 0.11 & 0.07 & 0.04 & 0.03 & 0.02 & 0.01 & 0.01 & 0.00 & 0.00 \\
\hline 0.96 & 0.26 & 0.14 & 0.09 & 0.06 & 0.04 & 0.03 & 0.02 & 0.01 & 0.00 & 0.00 \\
\hline 0.95 & 0.31 & 0.17 & 0.10 & 0.07 & 0.05 & 0.03 & 0.02 & 0.01 & 0.01 & 0.00 \\
\hline 0.94 & 0.35 & 0.19 & 0.12 & 0.08 & 0.06 & 0.04 & 0.03 & 0.01 & 0.01 & 0.00 \\
\hline 0.93 & 0.39 & 0.22 & 0.14 & 0.10 & 0.07 & 0.04 & 0.03 & 0.02 & 0.01 & 0.00 \\
\hline 0.92 & 0.42 & 0.24 & 0.16 & 0.11 & 0.07 & 0.05 & 0.03 & 0.02 & 0.01 & 0.00 \\
\hline 0.91 & 0.45 & 0.26 & 0.17 & 0.12 & 0.08 & 0.06 & 0.04 & 0.02 & 0.01 & 0.00 \\
\hline 0.90 & 0.47 & 0.29 & 0.19 & 0.13 & 0.09 & 0.06 & 0.04 & 0.02 & 0.01 & 0.00 \\
\hline 0.85 & 0.57 & 0.38 & 0.26 & 0.18 & 0.13 & 0.09 & 0.06 & 0.04 & 0.02 & 0.00 \\
\hline 0.80 & 0.64 & 0.44 & 0.32 & 0.23 & 0.17 & 0.12 & 0.08 & 0.05 & 0.02 & 0.00 \\
\hline 0.75 & 0.69 & 0.50 & 0.37 & 0.27 & 0.20 & 0.14 & 0.10 & 0.06 & 0.03 & 0.00 \\
\hline 0.70 & 0.73 & 0.55 & 0.41 & 0.31 & 0.23 & 0.17 & 0.11 & 0.07 & 0.03 & 0.00 \\
\hline
\end{tabular}

\section{References}

1. Arnold, J.R., Introduction to Materials Management, Englewood Cliffs, N.J., Prentice Hall, 1998.

2. Brown, R.G., Advanced Service Parts Inventory Control, Thetford Center, Vt., Materials Management Systems, 1981.

3. $\quad$ Orlicky, J., Materials Requirements Planning. New York, McGraw Hill Co., 1975.

4. Simchi-Levi, D., P. Kaminsky and E. Simchi-Levi, Designing and Managing the Supply Chain, Boston, McGraw-Hill, 2000.

5. Thomopoulos, N., Strategic Inventory Management and Planning, Carol Stream Il., Hitchcock Publishing Co. , 1990. 
Notes 